\title{
Education Between GovTech and Civic Tech
}

\author{
https://doi.org/10.3991/ijet.v16i04.18769 \\ Masami Yoshida ( $₫)$ \\ Chiba University, Chiba, Japan \\ yoshida-mefaculty.chiba-u.jp \\ Thapanee Thammetar \\ Silpakorn University, Nakhon Pathom, Thailand
}

\begin{abstract}
In the recent movement towards smart societies, smart governments supported by GovTech and smart cities developed through Civic Tech have become known as dominant structures enabled by information and communications technology. Since GovTech and Civic Tech share the goal of giving citizens better and safer lives through their engagement with government and technology, the development of online public services is characterized by the use of collaborative production methods involving various stakeholders and players. Open data, collaboration, and systematic teamwork are key to understanding this production of heterarchical structures. This study reviews previous cases of collaboration between GovTech and Civic Tech, identifies the dominant mechanisms of the smart society, and summarizes existing pedagogical and industrial theoretical systems, mindsets, and skillsets with the aim of developing content for a university course. Double loop learning, design thinking, the Agile methodology, and the lean principle are identified as theoretical systems. Our findings are arranged so that they can be applied in the content of a university-level educational technology course, which we designed to develop students' transformative competencies to enable them to become active citizens. In addition, we compared the processes involved in observed theoretical systems and conventional pedagogical theories to clarify the differences in their mechanisms. We conclude with a discussion of the need to recognize frameworks of different paradigms to prepare students for transformative social activities.
\end{abstract}

Keywords-Civic Tech, GovTech, smart society, university course content

\section{Introduction}

Advanced technology and innovations such as drastic increases in computing power are contributing to improvements in our daily lives. Innovative modern technology enables governments to provide services to citizens, businesses, employees, and other governmental agents [1]. Moreover, it is critical that we leverage information and communications technology to its fullest to gain new knowledge and create new values by making connections between governments and citizens, thereby effectively and 
efficiently resolving issues in society and creating better lives for citizens. Governments worldwide are seeking new and advanced technologies to link governments to citizens and firms and to facilitate online information sharing [2].

On the other hand, in light of the proliferation of social issues and the lack of resources to address them all, many government leaders have recognized the opportunities inherent in harnessing highly motivated and diverse citizens to create a better future. O'Reilly called this movement "Government 2.0" [3]. It aims to use all available technologies and methods to open the public sector, creating a new level of transparency with the intention of changing how public services operate and giving citizens the opportunity to participate in public deliberation and decision-making in a variety of ways. Overcoming social issues by encouraging various stakeholders to share a common vision of the future will be vital to realizing future societies through digitalization.

Data science technologies such as big data and blockchain are poised to revolutionize government and create a new generation through the smartification of public services [4]. There is also hope that social media can help reinvigorate civic engagement by providing new possibilities for bottom-up, self-organizing activity [5].

\subsection{GovTech}

E-government- - the application of technology to improve government efficiency or modernize systems - has been disseminated worldwide [6]. Siodmok [7] created a taxonomy of intervention styles to categorize where innovation through government can be effective (Table 1). These intervention styles imply possibilities for cultivating various communication opportunities with citizens.

Table 1. Styles of Government Intervention

\begin{tabular}{|c|c|}
\hline Level of Intervention & Style \\
\hline Low & Stewardship \\
\hline$\wedge$ & Leading, influencing, and informing \\
\hline I & Procurement, purchasing, and buying powers \\
\hline I & Providing and commissioning services \\
\hline I & Funding, taxes, tariffs, and subsidies \\
\hline $\mathrm{v}$ & Regulation \\
\hline Large-scale & Laws \\
\hline
\end{tabular}

"GovTech" (a portmanteau of the words "government" and "technology") refers to the strategy invented to increase efficiency in administration by digitalizing work processes or incorporating new technological tools [8]. GovTech is a whole-government approach to public sector modernization that promotes simple, accessible, and efficient government. It aims to promote the use of technology to transform the public sector; improve service delivery to citizens and businesses; and increase efficiency, transparency, and accountability [9].

Governments are the primary beneficiaries of GovTech. GovTech's measures of success are efficiency gains and saved costs. Policies regarding open government data 
and government transparency have been developed to enable citizens' access to information and participation in government $[10,11]$.

This world trend and platform for reformers was presented as a multilateral initiative of open government partnership (OGP) at a United Nations General Assembly meeting in 2011 [12]. For example, in the United States, MuckRock developed an online tool that made it easier for citizens to request public records [13]. In addition, participatory civic design frameworks with eight designed public dialogues were proposed by McDowell. These frameworks included conversations about designing for the margins, collaboration, equity, systemic change, ecological and network effects, analog and digital, different ways of expression, and healing [14]. These dialogues clarified how GovTech should embody Government 2.0. The efficiency of GovTech is thus deemed a more socialized point of view.

\subsection{Civic tech}

The public interfaces of the smart city are often described as Civic Tech (an abbreviation of the phrase "civic technology"). The term "Civic Tech" is used to refer to civic products - such as web applications, civic portals, and open data repositories, among other tools - that leverage smart city and governmental data and make such data available for public consumption [15]. The Knight Foundation [16] identified two forms of Civic Tech: organizations working towards community action, and organizations working towards open government. Civic Tech focuses on informing citizens, connecting them with each other, and encouraging them to engage with their governments to work together for the public good [8]. Numerous non-governmental organizations, active citizens, and socially minded businesses throughout the world are developing digital tools that can be used to increase government transparency and efficiency and improve the lives of communities in which they are involved [17].

Civic Tech asserts the cardinal importance of close collaboration among governments, various individuals which include technologically naïve citizens, and software engineers. Usually, Civic Tech organizations offer them opportunities to receive small grants and operational support from the government. Civic Tech also encompasses a range of projects that use open government data to act in the public good [18].

Since GovTech focuses heavily on participatory governance to develop policies that impact communities, Civic Tech faces a challenge in achieving success drawn from citizen engagement [19]. To address this, a previous study [20] proposed three important factors: 1) establishing trust and accountability for Civic Tech; 2) creating opportunities for underserved citizens by constructing networks of support through shared experience; and 3) developing an assets-based approach that begins by rethinking design and research methods in community settings to assemble their strengths into new combinations. 


\subsection{Combining GovTech and civic tech}

Although GovTech and Civic Tech have different stakeholders, the two overlap in terms of the citizens targeted by the online information they provide. Ransbeeck [8] noted that GovTech and Civic Tech should not be seen as opposing tools and work best when used together. Civic Tech helps citizens become involved in decision-making, and GovTech helps governments respond more efficiently to this input. Indeed, the implementation of a Civic Tech tool that was embraced by the host government was positively valued in five U.S. municipal Civic Techs organizations [21]. While emerging Civic Tech for collaborative governance differs from e-government, collaborative governance also aims to achieve more responsive and inclusive governance [22].

While Civic Tech primarily refers to nongovernmental initiatives, Code for America and similar organizations around the world allow for citizen-focused technology. They aim to develop and implement projects by and with public bodies in an attempt to reach out to citizens and increase their engagement and participation [23].

National and local governments are attempting to overhaul procurement procedures in order to more effectively partner with Civic Tech. Part of Civic Tech's promise is its potential to circumvent inefficient bureaucracies by facilitating a more participatory and open relationship between citizens and civic organizations, governmental or otherwise [24].

\subsection{Open data and open source}

Open collaboration has emerged as the practice of collaboratively developing software products in government to create innovative solutions to complex public sector problems. Rather than outsourcing to contractors to produce an online service, internally developed code is uploaded to GitHub, a social code hosting service, where external software engineers are invited to reuse the code or suggest changes to improve it. Governments can thus take advantage of the willingness of civic co-software engineers [25].

Since its debut in 2008, GitHub has provided a web-based code hosting service in an open development environment that makes project activity visible through notifications and a simple interface [26]. Using GitHub can drastically increase the number of touchpoints with stakeholders in a project as well as their communication with one another [27], meaning that GitHub can be used by non-technical users. Due to GitHub's popularity, generated by the free and open-source software movement, the use of GitHub in GovTech involves social knowledge creation, open science, open collaboration, and open governance that moves beyond the original core stakeholders [28]. Recently, the governments of many countries have encouraged software engineers to create and share open-source code on GitHub and allow third parties to share their changes to the code [25].

Governments interested in open data can also make data available to the public under an open-source license [29]. Open data is thought to be useful in involving citizens 
more directly in decision-making processes and enabling their collaboration on technological projects [30].

\subsection{Hackathon}

A "hackathon" (a portmanteau of the words "hack" and "marathon") is a group activity organized by diverse creators-such as software engineers, designers, and project planners - and is the most common example of Civic Tech [31]. Hackathons involve exploratory joint work that occurs in the production process of prototyping an online service, system, or application [32].

Recent civic hackathons have been time-limited events (typically lasting hours or days) launched at a specific venue where enthusiasts, government workers, interested citizens, and the private sector can collaborate. The goal of a civic hackathon is to leverage open government data to develop software applications that address issues of shared civic importance [33]. Hackathons encourage collaboration across multiple disciplines as new ideas are generated [34]. Usually, hackathons are organized to solve a problem, and the wide acceptance of participants in civic hackathons is used to facilitate methods of citizen-driven engagement [35]. These bottom-up and non-hierarchical approaches may be more likely to create sustainable change. A recently published report [36] emphasized the importance of citizens' active involvement in this process, called "co-creation."

After OGP, civic hackers can use their coding skills to work with municipal open data to program apps and find solutions to improve citizen life. From Mayor Bloomberg's 2011 "Reinvent NYC" civic hackathon to the City of Paris's 2016 urban security-focused event to Toronto, Canada's 2015 traffic jam event, local governments worldwide are using civic hackathons to deploy open data to fix their cities [37]. Communication in civic hackathons has taken place on various communication channels, such as Twitter, Slack, and GitHub Gist (a platform to share code snippets and discussions with others), which often affects their product designs.

In this study, we collected cases of smart societies; investigated the structure and mechanisms of collaboration between GovTech and Civic Tech; and identified the core mindsets, skillsets, and theoretical systems used. Our findings are arranged such that they can be utilized in the content of a university-level educational technology course, which we designed to develop students' transformative competencies to enable them to become active citizens. Therefore, this study does not involve analyses of cases for ethnographic purposes. The analysis is based on education technology and attempts to depict a systematic structure based on these cases. Technology-enabled, large-scale citizen engagement has enormous potential to advance smart societies. The course is thus intended to offer a general education that involves citizenship education as well as educational technology. The course's target students include not only the technologically savvy but also the technologically naïve living in a smart society. 


\section{Concerning Pedagogy}

In a recent case of collaboration between GovTech and Civic Tech, the Tokyo city government and Code for Japan released a COVID-19 information website as a municipal service on March 4, 2020 (https://stopcovid19.metro.tokyo.lg.jp/en). Code for Japan proposed the following action mindset on March 3 to organize collaboration with heterarchical individuals [38] (translated by the author):

Why we are here

To protect the life and health of citizens in Tokyo.

To disclose accurate data to people insideloutside the country.

To show the concrete effects of producing a proper product by a proper method through a collaborative process.

Action principles to develop a website

User perspective.

The meaning of information arises when it reaches people.

Recognize the importance of user experiences.

Engage in numerical analysis through the collection of access, terms used in retrievals, and SNS (social network service) data.

Although it is not suitable to have strict rules or codes for effective collaboration in a casual organization, a common mindset must be shared to ensure efficient individual contributions. Since this mindset does not involve any political or technological specifications, individuals of many different backgrounds can understand the goal of the project. Participants of the hackathon deemed the mindset indispensable in gaining each individual's trust and ensuring their taking immediate action to participate in the project [39]. This comprehensive involvement in the smart society enables students in our target course to develop competencies that will enable them to collaborate in the transformative society.

There is also another method for enhancing the smart society: namely, launching underrepresented talent into successful careers by providing a model for professional activities, called "tech apprenticeship." In other words, GovTech and Civic Tech can provide entry-level workers with a more stable pipeline into medium-skilled jobs in the growing tech workforce, a field that is creating many good jobs [40]. The present study also focuses on the structure and systems of software engineering collaboration. While the smart society is often discussed in terms of citizenship and software engineering, it is also important to include enabling social competencies, such as media information literacy [41] and digital literacy [42].

The following systems are identified as core materials that can be used by students to understand the smart society and activity incorporating both GovTech and Civic Tech.

\subsection{Double loop learning}

Double loop learning is an educational concept and process that involves the reconsideration of goals or decision-making rules. The first loop uses the existing goal or decision-making rule, while the second loop enables its modification [43] (Figure 1). 


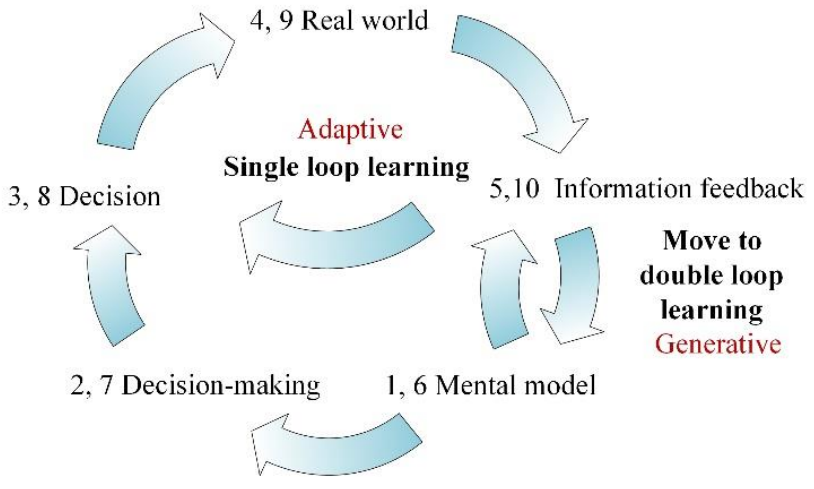

Fig. 1. Double loop learning process.

The theory focuses on living problems that are complex and poorly structured and change as problem-solving advances. An important aspect of this concept is the distinction between an individual's espoused theory and their "theory-in-use." Bringing these two into congruence is a primary concern of double loop learning.

The action theory learning process has four basic steps. The processes outlined in Figure 1 are shown in parentheses.

1. Discovery of espoused theory and theory in use (1-5);

2. Invention of new meanings (6);

3. Production of new actions (7-8); and

4. Generalization of results (9-10).

\subsection{Design thinking}

Design thinking is a methodology for group creative and practical problem-solving that begins by collecting ideas from members. In this way, it resembles "ideathons" (a portmanteau of the words "idea" and "marathon"): short brainstorming events that involve exchanging ideas in order to identify a project's target. Design thinking is a non-linear, iterative process that includes the following five phases: empathizing, defining, ideating, prototyping, and testing. It is most useful for tackling problems that are ill-defined or unknown [44] (Figure 2). The "emphasize" stage (1) involves processing activities to understand and imagine the users of an intended product; in the "ideate" stage, a group makes a decision to select one solution (3); and the test stage (5) involves the innovation process, in which a group performs various trials to arrive at the goal product. The adjustment process of double loop learning is involved in design thinking, in which a team redefines problems and creates innovative solutions to prototype and test [45]. 


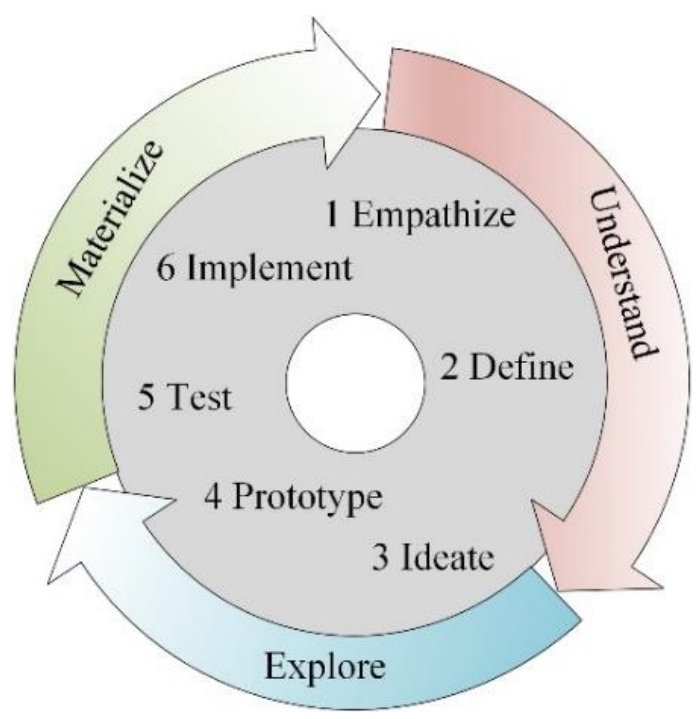

Fig. 2. Design thinking steps.

Collaboration is an integral part of design thinking, which is both a process and a mindset. It is therefore logical to examine the concept of collaborative governance in design thinking [46]. Collaborative governance aims to achieve responsive and inclusive governance, and GovTech and Civic Tech are recognized to foster, embed, and encourage collaborative governance [6].

As the nature of design thinking is organized by the various talents of group members, it is more suitable for improving a system than for developing one [47].

\subsection{Agile Methodology}

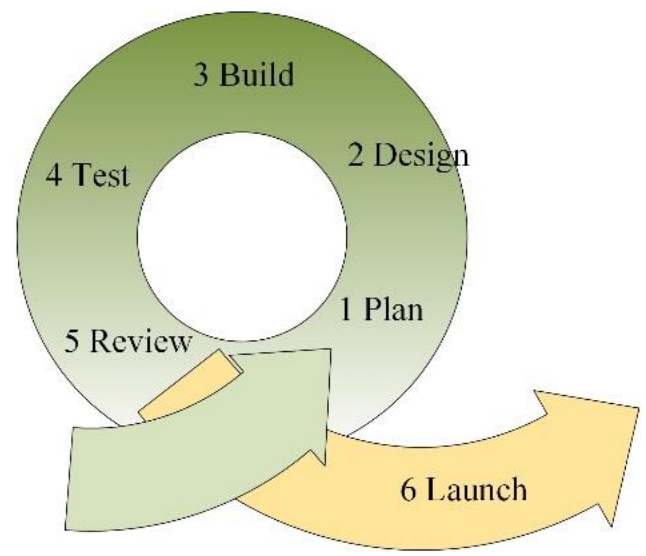

Fig. 3. One iteration of a constant cycle in the Agile methodology. 
The Agile methodology is a type of project management process mainly used in software development in which demands and solutions evolve through the collaborative effort of self-organizing and cross-functional teams and their customers [48]. The Agile methodology involves the continuous iteration of development and testing, whereas the traditional production method (the waterfall methodology) uses a planned sequential order wherein the team only moves to the next phase of development or testing after successfully completing the previous step [49]. An Agile project is split into short and constant cycles called "sprints," and cycles continue to change as the project takes form (Figure 3). This change management technique is an integrated part of the Agile methodology. While Civic Tech frequently involves coding, it is inclusive, user-centered, agile, and open to different types of collaboration [50].

Double loop learning has been used in Agile methodology [51], particularly in discussions of the management of software production [52], hackathons [53, 54], and public management [55].

\subsection{Lean principle}

Initially, the lean principle was introduced in manufacturing practices, but it has recently transformed the world of knowledge work and management. The lean principle encourages working towards continuous improvement and is based on the fundamental idea of having respect for people. The five steps of the lean principle process are proposed in [56] and displayed in Figure 4.

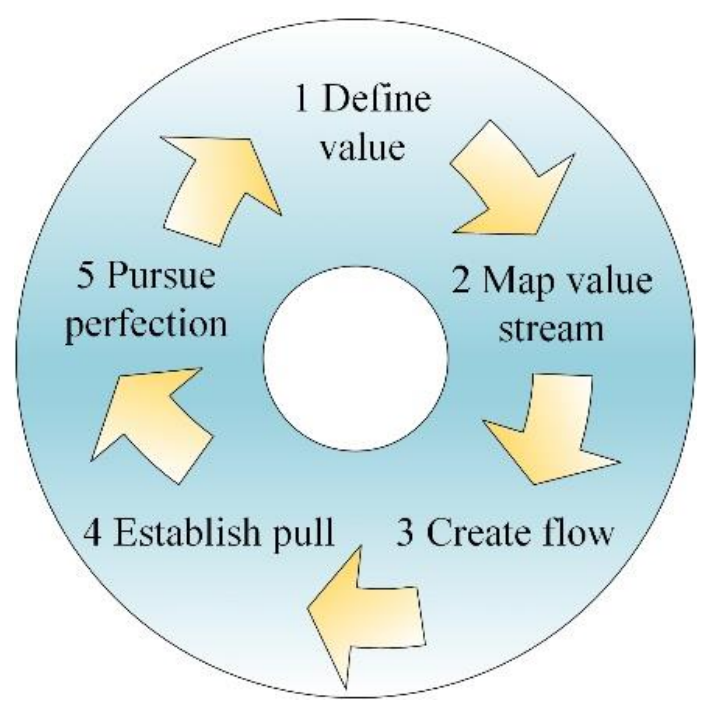

Fig. 4. Lean principle process.

While the core premise of the lean principle is eliminating waste, it takes effort to identify waste and implement best practices. Waste can be defined as any production 
process or activity that is without value-for example, overproduction, defects, and waiting during production activities. The lean principle emerged just after Agile methodologies; the goals of Agile were aligned with those of the lean principle and often applied in projects that emerged on GitHub [57]. Moreover, the lean principle has been combined with DMAIC (define, measure, improve, and control) [58] from the Six Sigma methodologies to eliminate waste and improve processes [59] and has become the most popular strategy in the manufacturing and public sectors [60]. A previous study [61] also reported beneficial effects for startups that used design thinking before introducing the lean principle.

\section{Discussion}

In this section, we discuss lateral and potential factors that can impact or support activities intended to move toward the smart society.

\subsection{X-tech}

In its fifth science and technology basic plan, the Japanese Cabinet proposed an initiative called Society 5.0 [62]. This initiative aimed to create a super-smart society that used digital technologies to provide necessary items and services to citizens who required them and enable citizens to live active and comfortable lives thanks to high-quality services. The Japanese government related the initiative to the implementation of the United Nations' Sustainable Development Goals (SDGs) and listed "creating a global future through Society 5.0" as a recommended action [63].

Together with this movement, Keidanren - the dominant business federation in Japan - depicted a proactive vision of using Society 5.0 to achieve the SDGs [64]. It included 10 systems of Society 5.0, 17 goals of the SDGs, 24 X-Techs, and 17 key technologies (Figure 5). GovTech and Civic Tech are dominant X-Techs that are challenging various areas to innovate their industrial structures and systems using digital technologies, including FinTech (finance), AgriTech (agriculture), and EdTech (education). Therefore, government programs and citizen activities are no longer separated, and our social progress proves that they work best when used together under the umbrella of the SDGs. 


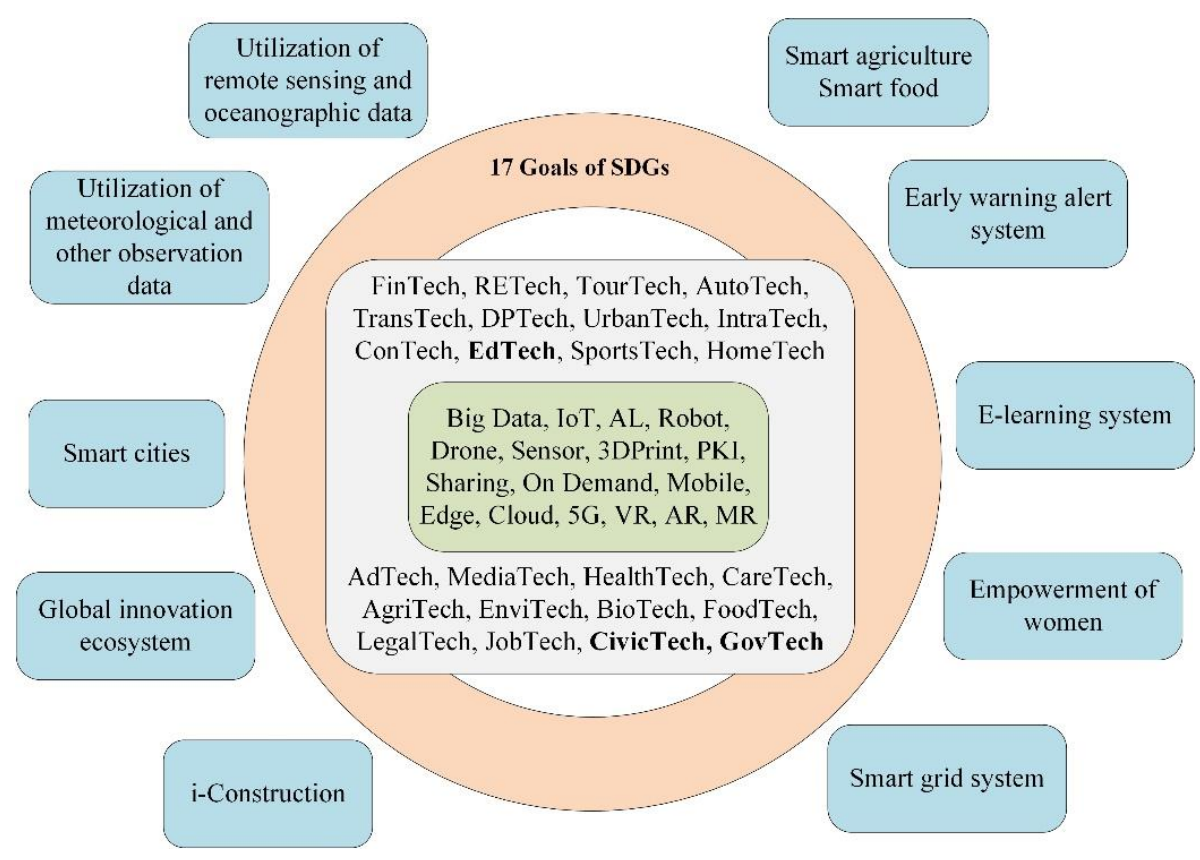

Fig. 5. Framework of Society 5.0 and Sustainable Development Goals.

\subsection{SDGs}

International discussions are proceeding regarding the implementation of the United Nations' SDGs [65], which were adopted in September 2015 as guideposts for the entire world. While their driving principle is to realize peace and prosperity for all people and the planet by responding to challenges with an inclusiveness that "leaves no one behind" [66], the Japanese government has incorporated the guiding principles for the implementation of SDGs in the following four action areas:

- Creating a global future through Society 5.0

- Enabling solutions using global data

- Promoting cooperation at a global level

- Cultivating human resources to undertake science, technology, and innovation efforts for SDGs.

Achieving the SDGs requires GovTech in which governments and public sectors are more agile, collaborate across agency boundaries and national borders, develop digitally transforming deliveries of public services, and harness disruptive technologies for new solutions to hitherto-unsolved problems [67]. The implementations of Civic Tech projects also frequently have close relationships with the SDGs [68, 69]. 


\subsection{MOOCs}

Although GovTech and Civic Tech have been considered tools for improving the "political fabric" (debates, concertation, legislative processes, elections, and so on), EdTech has opened the door to continuing citizen activity over the long term, which implies new ways of teaching, learning, sharing, and creation [70].

The worldwide EdTech market is estimated to have a $13.9 \%$ compound annual growth rate [71]. Massive open online courses (MOOCs) are an example of EdTech as well as an integral form of online services. EdTech has fostered diversity in education, particularly through online education methods that involve the concept of "learning over education" (i.e., learning outside of the conventional education system). MOOCs can also be used to learn about smart cities and related technologies as well as communication [72].

\section{Conclusion}

In the field of education, various objective-oriented theories and design systems have been used in which the initial stage involves defining the target of the project and designing the project process and evaluation criteria. However, we now use other systems that begin with investigation or execution.

For example, the ADDIE (analysis, design, development, implementation, and evaluation) system [73] for lesson design under behaviour theory begins by defining the target and overall procedure of a lesson to teach prepared content. However, the 5E (engage, explore, explain, elaborate, and evaluate) system [74], which is based on constructivist theory, aims to build a student's own understanding during a lesson that includes target searching. The PDCA (plan, do, check, and act) system is also used in education, but it has been considered for replacement with the OODA (observe, orient, decide, and act) system, which prioritizes flexible decision-making [75].

Another similarity between education and the smart society can be found in the style of systems used, namely cyclic and loop systems. This means that most projects have continuous phases. Therefore, if students understand the mindset and system structures, they can prepare for participation and contribution in the next phase.

Table 2. Results of Cases Including Other Systems in GovTech and Civic Tech Activities

\begin{tabular}{|c|l|c|c|c|c|l|}
\hline & \multicolumn{1}{|c|}{ System } & A & B & C & D & \multicolumn{1}{|c|}{ Characteristics } \\
\hline A & Double loop learning & - & & & & $\begin{array}{l}\text { Change espoused theory, problem-solving } \\
\text { procedure }\end{array}$ \\
\hline B & Design thinking & $\mathrm{v}$ & - & & & $\begin{array}{l}\text { Collaboration method, design project, exchange of } \\
\text { ideas }\end{array}$ \\
\hline C & Agile methodology & $\mathrm{v}$ & $\mathrm{v}$ & - & & Production method, customer opinions, iterative \\
\hline D & Lean principle & & $\mathrm{v}$ & $\mathrm{v}$ & - & $\begin{array}{l}\text { Manufacturing method, improvement, decreasing } \\
\text { waste }\end{array}$ \\
\hline
\end{tabular}

Note) v: possible to appear in another system

Although these systems have different application purposes, they are not always applied independently. It is possible that some phases in a system will involve another 
system. We summarize the reported relationships in previous cases of the smart society in Table 2 to provide comprehensive understandings of systems for students.

As a challenge in the near future, we intend to investigate EdTech cases that teach content related to the smart society, GovTech, and Civic Tech.

\section{$5 \quad$ Conflicts of Interest}

The authors declare no conflicts of interest.

\section{Acknowledgement}

This work was supported by JSPS KAKENHI, Grant-in-Aid for Challenging Research (Pioneering), Grant Number 20K20512.

\section{$7 \quad$ References}

[1] Almaiah, M., Al-Khasawneh, A., Althunibat, A., and Khawatreh, S. (2020). Mobile government adoption model based on combining GAM and UTAUT to explain factors according to adoption of mobile government services. International Journal of Interactive Mobile Technologies, 14(3): 199-225. https://doi.org/10.3991/ijim.v14i03.11264

[2] Alqaralleh, B., Al-Omari, A., and Alksasbeh, M. (2020). An integrated conceptual model for $\mathrm{m}$-Government acceptance in developing countries: The case study of Jordan. International Journal of Interactive Mobile Technologies, 14(6), 5-14. https://doi.org/10. 3991/ijim.v14i06.11449

[3] O'Reilly, T. (2009). Gov 2.0: The promise of innovation. Available: https://www.forbes. com/2009/08/10/government-internet-software-technology-breakthroughs-oreilly.html\#72 d2e0153b7b (accessed August 10, 2020)

[4] Engin, Z., and Treleaven, P. (2019). Algorithmic government: Automating public services and supporting civil servants in using data science technologies. The Computer Journal, 62(3): 448-460. https://doi.org/10.1093/comjnl/bxy082

[5] Uldam, J., and Kaun, A. "Theorizing civic engagement and social media," in Social Media Materialities and Protest: Critical Reflections, Poell, T., Ed. London, UK: Routledge, 2018. https://doi.org/10.4324/9781315107066-8

[6] Gilman, H. R. (2017). Civic Tech for urban collaborative governance. PS - Political Science \& Politics, 50(3): 744. https://doi.org/10.1017/s1049096517000531

[7] Conway, R., Burbidge, I., Timmons, L., and Maani, S. "Move fast and fix things. How to be a public entrepreneur," Royal Society for the Encouragement of Arts, Manufactures and Commerce, London, UK, 2018

[8] Ransbeeck, W. V. (2020). What's the difference between Civic Tech and GovTech? Available: https://digileaders.com/whats-the-difference-between-civic-tech-and-govtech/ (accessed June 3, 2020)

[9] World Bank. (2020). GovTech: Putting people first. Available: https://www.worldbank. org/en/topic/governance/brief/govtech-putting-people-first (accessed April 9, 2020)

[10] Amin, L. "How open is the UK government? UK open governance scorecard results," Transparency International UK, London, UK, 2015 
[11] Brown, M. M. (2007). Understanding e-government benefits: An examination of leading-edge local governments. The American Review of Public Administration, 37(2): 178-197. https://doi.org/10.1177/0275074006291635

[12] Open Government Partnership. (2020). Open government declaration. Available: https:// www.opengovpartnership.org/process/joining-ogp/open-government-declaration/ (accessed June 4, 2020)

[13] Capeloto, A. (2019). Agency perspectives on online public records request portals. The Journal of Civic Information, 1(1): 59-74. https://doi.org/10.32473/joci.v1i1.115659

[14] McDowell, C. (2016). Crisis or opportunity? A dialogue on democracy, inclusion, and community. The 13th Annual Ikeda Forum for Intercultural Dialogue, Cambridge, MA

[15] Vlachokyriakos, V., Crivellaro, C., Le Dantec, C. A., Gordon, E., Wright, P., and Olivier, P., Digital civics: Citizen empowerment with and through technology. Proceedings of the 2016 CHI Conference Extended Abstracts on Human Factors in Computing Systems, May 7-12 2016, California, pp. 1096-1099. https://doi.org/10.1145/2851581.2886436

[16] Patel, M., Sotsky, J., Gourley, S., and Houghton, D. "The emergence of Civic Tech: Investments in a growing field," Knight Foundation, Miami, FL, 2013

[17] Mačiulienè, M., and Skaržauskienè, A. (2019). Building the capacities of civic tech communities through digital data analytics. Journal of Innovation \& Knowledge, in Press, Available: https://doi.org/10.1016/j.jik.2019.11.005

[18] Gordon, E., and Mihailidis, P. Civic media: Technology, design, practice. MA: MIT Press, 2016

[19] Fung, A. Empowered participation: Reinventing urban democracy. NJ: Princeton University Press, 2009

[20] Dickinson, J., Díaz, M., Le Dantec, C. A., and Erete, S., The cavalry ain't coming in to save us: Supporting capacities and relationships through Civic Tech. Proceedings of the ACM on Human-Computer Interaction, May 4-9 2019, Glasgow, UK, pp. 1-21

[21] Shaw, E. (2018). Skipping ahead to the good part: The role of civic technology in achieving the promise of e-government. JeDEM - eJournal of eDemocracy and Open Government, 10(2): 74-96. https://doi.org/10.1145/3359225

[22] Gilman, H. R. (2017). Civic Tech for urban collaborative governance. Ps - Political Science \& Politics, 50(3): 744-750. https://doi.org/10.1017/s1049096517000531

[23] Rumbul, R., and Shaw, E. (2017). Civic Tech cities. Available: https://research.mysociety .org/publications/civic-tech-cities (accessed September 2, 2020)

[24] Gordon, E., and Lopez, R. A. (2019). The practice of Civic Tech: Tensions in the adoption and use of new technologies in community-based organizations. Media and Communication, 7(3): 57-68. https://doi.org/10.17645/mac.v7i3.2180

[25] Mergel, I. (2015). Open collaboration in the public sector: The case of social coding on GitHub. Government Information Quarterly, 32(4): 464-472. https://doi.org/10.1016/j.gi q.2015.09.004

[26] Kalliamvakou, E., Damian, D., Blincoe, K., Singer, L., and German, D. M., Open source-style collaborative development practices in commercial projects using GitHub. 2015 IEEE/ACM 37th IEEE International Conference on Software Engineering, May 16-24 2015, Florence, Italy, pp. 574-585. https://doi.org/10.1109/icse.2015.74

[27] Grassi, P., Garcia, M., and Boeckl, K. (2017). Government adopts an industry approach to open-source collaboration. Computer, 50(11): 78-81. https://doi.org/10.1109/mc.2017.404 1352

[28] Longo, J., and Kelley, T. M. (2016). GitHub use in public administration in Canada: Early experience with a new collaboration tool. Canadian Public Administration, 59(4): 598-623. https://doi.org/10.1111/capa.12192

[29] Schrock, A., and Shaffer, G. (2017). Data ideologies of an interested public: A study of grassroots open government data intermediaries. Big Data \& Society, 4(1): 2053951717690750. https://doi.org/10.1177/2053951717690750 
[30] Yu, H., and Robinson, D. G. (2012). The new ambiguity of "Open Government." UCLA Law Review, 59(178): 178-208

[31] Majorek, M., and du Vall, M., Civic technology for education: Analysis and evaluation of selected initiatives. SHS Web of Conferences, 2017, p. 01015. https://doi.org/10.1051/shs conf $/ 20173701015$

[32] Gregg, M. (2015). Hack for good: Speculative labour, app development and the burden of austerity. The Fibreculture Journal, (25): 183-201. https://doi.org/10.15307/fcj.25.186.201 $\underline{5}$

[33] Johnson, P., and Robinson, P. (2014). Civic hackathons: Innovation, procurement, or civic engagement? Review of Policy Research, 31(4): 349-357. https://doi.org/10.1111/r opr.12074

[34] Angelidis, P., Berman, L., Casas-Perez, M. d. 1. L., Celi, L. A., Dafoulas, G. E., Dagan, A., Escobar, B., Lopez, D. M., Noguez, J., and Osorio-Valencia, J. S. (2016). The hackathon model to spur innovation around global mHealth. Journal of Medical Engineering \& Technology, 40(7-8): 392-399. https://doi.org/10.1080/03091902.2016.12 $\underline{13903}$

[35] Soliz, S., and Young, S. D. Feasibility of a citizen-driven hackathon to increase public engagement and solutions to address the opioid crisis. Journal of Substance Use: 6 . https ://doi.org/10.1080/14659891.2020.1753833

[36] Toros, K., Kangro, K., Lepik, K. L., Bugarszki, Z., Sindi, I., Saia, K., and Medar, M. Co-creation of social services on the example of social hackathon: The case of Estonia. International Social Work, 14. http://doi.org/10.1177/0020872820904130

[37] Robinson, P. J., and Johnson, P. A. (2016). Civic hackathons: New terrain for local government-citizen interaction? Urban Planning, 1(2): 65-74. https://doi.org/10.17645/up . $\mathrm{v} 1 \mathrm{i} 2.627$

[38] Takasu, M. (2020). Official website for COVID-19 prevalence mesures was developed by open source. Available: https://business.nikkei.com/atcl/seminar/19/00058/031000042/?P $=2($ accessed March 12, 2020)

[39] Takasu, M. (2020). The new corona virus countermeasure website of Tokyo city was developed by open source. Available: https://business.nikkei.com/atcl/seminar/19/00058/ 031000042/ (accessed March 12, 2020)

[40] Messina, J., and Dvorkin, E. "Expanding tech apprenticeships in New York City," Center for an Urban Future, New York, 2019

[41] Yoshida, M., and Iijima, J. (2019). Media information literacy to produce collaborative social capital. International Journal of Information and Education Technology, 9(12): 868-873. https://doi.org/10.18178/ijiet.2019.9.12.1319

[42] Education Superhighway. (2020). Case study: Chicago connected. Available: https://digi talbridgek12.org/toolkit/deploy/chicago-connected/ (accessed August 21, 2020)

[43] Argyris, C. Increasing leadership effectiveness. New York: John Wiley \& Sons Inc, 1976

[44] Dam, R. F., and Siang, T. Y. (2020). 5 stages in the design thinking process. Available: https://www.interaction-design.org/literature/article/5-stages-in-the-design-thinking-proce ss (accessed September 2, 2020)

[45] Mintrom, M., and Luetjens, J. (2016). Design thinking in policymaking processes: Opportunities and challenges. Australian Journal of Public Administration, 75(3): 391-402. https://doi.org/10.1111/1467-8500.12211

[46] Millan, S. B., "Design thinking and collaborative governance for public service innovation. An application in civic technology," D.P.A., National College of Public Administration and Governance, University of the Philippines Diliman, Diliman, Philippines, 2019. https://doi.org/10.17501/26731037.2019.1103

[47] Sakakibara, K. (2020). Why design thinking produce a number of junk ideas? Available: https://note.com/studies_ceo/n/nd3c499f24052 (accessed August 21, 2020) 
[48] Muslihat, D. (2018). Agile methodology: An overview. The art of iterative and incremental software development. Available: https://zenkit.com/en/blog/agile-methodolo gy-an-overview/ (accessed September 1, 2020)

[49] Al-Saqqa, S., Sawalha, S., \& AbdelNabi, H. (2020). Agile software development: Methodologies and trends. International Journal of Interactive Mobile Technologies, 14(11), 246-270

[50] Knutas, A., Palacin, V., Maccani, G., and Helfert, M. Software engineering in civic tech: A case study about Code for Ireland. 2019 IEEE/ACM 41st International Conference on Software Engineering: Software Engineering in Society (ICSE-SEIS), May 29-31 2019, Montreal, Canada, pp. 41-50. https://doi.org/10.1109/icse-seis.2019.00013

[51] Pawar, Y. (2016). Effective Agile performance management with double loop learning. Available: https://upraise.io/blog/effective-agile-performance-management-double-loop -learning/ (accessed August 23, 2020). https://doi.org/10.1016/j.infsof.2007.02.012

[52] McAvoy, J., and Butler, T. (2007). The impact of the Abilene Paradox on double-loop learning in an Agile team. Information and Software Technology, 49(6): 552-563

[53] Garo, H., and Riera, J. (2020). Discovering civic educational hackathons: An exploratory study. Aloma: Revista de Psicologia, Ciències de l'Educació i de l'Esport, 38(1): 51-61

[54] Attia, C. (2019). @Mastercard: Achieving an agile work culture though hackathons. Available: https://medium.com/@cyrilBMA/mastercard-achieving-an-agile-work-culture -though-hackathons-c3e775cd9363 (accessed June 16, 2020)

[55] Van Dooren, W. (2011). Better performance management. Some single and double-loop strategies. Public Performance \& Management Review, 34(3): 420-433. https://doi.org/10 $.2753 / \mathrm{pmr} 1530-9576340305$

[56] Womack, J. P., Jones, D. T., and Roos, D., The machine that changed the world. New York: Simon \& Schuster Ltd, 1990

[57] Salo, R., Poranen, T., and Zhang, Z. Requirements management in GitHub with a lean approach. SPLST, October 9-10 2015, Tampere, Finland, pp. 164-178

[58] Snee, R. D., and Hoerl, R. W., Leading Six Sigma: A step by step guide based on experience at GE and other Six Sigma companies. NJ: Prentice Hall, 2003. https://doi.org/ $10.1108 / 02656710410530136$

[59] Tohidi, H., and Khedri Liraviasl, K. (2012). Six Sigma methodology and its relationship with lean manufacturing system. Advances in Environmental Biology, 6(2): 895-906

[60] Laureani, A., and Antony, J. (2019). Leadership and lean Six Sigma: A systematic literature review. Total Quality Management \& Business Excellence, 30(1-2): 53-81. https://doi.org/10.1080/14783363.2017.1288565

[61] Patton, J., and Economy, P., User story mapping: Discover the whole story, build the right product. CA: O'Reilly Media, Inc., 2014

[62] Government of Japan. (2016). The 5th science and technology basic plan. Available: https ://www8.cao.go.jp/cstp/english/basic/5thbasicplan.pdf (accessed August 16, 2020)

[63] Advisory Board for the Promotion of Science and Technology Diplomacy. (2017). Recommendation for the future STI as a bridging force to provide solutions for global issues. Available: https://www.mofa.go.jp/files/000255801.pdf (accessed August 15, 2020)

[64] Keidanren. (2017). Society 5.0 for SDGs. Available: https://www.keidanren.or.jp/en/poli cy/csr/2017reference2.pdf (accessed August 11, 2020)

[65] United Nations. (2019). 17 goals to transform our world. Available: https://www.un.org/ sustainabledevelopment/ (accessed August 1, 2020)

[66] Saner, R., Yiu, L., and Nguyen, M. (2020). Monitoring the SDGs: Digital and social technologies to ensure citizen participation, inclusiveness and transparency. Development Policy Review, 38(4): 483-500. https://doi.org/10.1111/dpr.12433 
[67] Ojo, A., Next generation government: Hyperconnected, smart and augmented. Working Conference on Virtual Enterprises, September 23-25 2019, Turin, Italy, pp. 285-294. https ://doi.org/10.1007/978-3-030-28464-0_25

[68] Hawken, S., Leao, S. Z., Gudes, O., Izadpanahi, P., Viswanath, K., and Petit, C. "Safer cities for women: Global and local innovations with open data and civic technology," in Open Cities | Open Data. Urban inclusion and social entrepreneurship, ed. Singapore: Springer, 2020. https://doi.org/10.1007/978-981-13-6605-5 4

[69] Kondo, Y., Miyata, A., Ikeuchi, U., Nakahara, S., Nakashima, K. I., Ōnishi, H., Osawa, T., Ota, K., Sato, K., and Ushijima, K. (2019). Interlinking open science and community-based participatory research for socio-environmental issues. Current Opinion in Environmental Sustainability, 39: 54-61. https://doi.org/10.1016/j.cosust.2019.07.001

[70] Douhard, L. (2016). When Civic Tech meets education \& culture. Available: https://for um.etalab.gouv.fr/t/when-civic-tech-meets-education-culture/2250 (accessed October 7 , 2018)

[71] Sato, M. (2015). What is the innovation in education by EdTech? Appeared nature of EdTech. IPSJ Magazine, 58(3): 176-179

[72] Gooch, D., Hudson, L., Barker, M., Wolff, A., and Petre, M., Mining a MOOC to examine international views of the "Smart City." 2017 IEEE SmartWorld, Ubiquitous Intelligence \& Computing, Advanced \& Trusted Computed, Scalable Computing \& Communications, Cloud \& Big Data Computing, Internet of People and Smart City Innovation (SmartWorld/SCALCOM/UIC/ATC/CBDCom/IOP/SCI), August 4-7 2017, CA, pp. 1-5. https://doi.org/10.1109/uic-atc.2017.8397591

[73] Reiser, R. A., and Dempsey, J. V., Trends and issues in instructional design and technology. Boston, MA: Pearson, 2012

[74] Bybee, R. W., Taylor, J. A., Gardner, A., Van Scotter, P., Powell, J. C., Westbrook, A., and Landes, N. (2006). The BSCS 5E instructional model: Origins and effectiveness. Colorado Springs, CO: BSCS, 5: 88-98

[75] Cordeiro, L. (2018). Cycle OODA X PDCA cycle in the decision making process. Available: https://www.researchgate.net/publication/327138597 CYCLE OODA X PD CA_CYCLE_IN_THE_DECISOIN_MAKING_PROCESS?channel=doi\&linkId=5b7c0f 01a6fdcc5f8b591c95\&showFulltext=true (accessed June 8, 2020). https://doi.org/10.10 $07 /$ springerreference 6568

\section{Authors}

Masami Yoshida is a Professor on the Faculty of Education, Chiba University, Japan. His major field is educational technology and education for international understanding.

Thapanee Thammetar is Associate Professor on the Faculty of Education, Silpakorn University, Thailand, and the Director of the Thailand Cyber University (TCU) Project, Ministry of Higher Education Science Research and Innovation, Thailand.

Article submitted 2020-09-22. Resubmitted 2020-11-01. Final acceptance 2020-11-05. Final version published as submitted by the authors. 